\title{
Precipitation from African Easterly Waves in a Coupled Model of the Tropical Atlantic
}

\author{
Hyodae SEO \\ Scripps Institution of Oceanography, La Jolla, California \\ MARKUS JOCHUM \\ National Center for Atmospheric Research, Boulder, Colorado \\ Raghu Murtugudde \\ ESSIC/DAOS, University of Maryland, College Park, College Park, Maryland \\ Arthur J. Miller and John O. RoAds \\ Scripps Institution of Oceanography, La Jolla, California
}

(Manuscript received 21 February 2007, in final form 17 August 2007)

\begin{abstract}
A regional coupled climate model is configured for the tropical Atlantic to explore the role of synopticscale African easterly waves (AEWs) on the simulation of mean precipitation in the marine intertropical convergence zone (ITCZ). Sensitivity tests with varying atmospheric resolution in the coupled model show that these easterly waves are well represented with comparable amplitudes on both fine and coarse grids of the atmospheric model. Significant differences in the model simulations are found in the precipitation fields, however, where heavy rainfall events occur in the region of strong cyclonic shear of the easterly waves only on the higher-resolution grid. This is because the low-level convergence due to the waves is much larger and more realistic in the fine-resolution simulation, which enables heavier precipitation events that skew the rainfall distributions toward longer tails. The variability in rainfall on these time scales accounts for more than $60 \%-70 \%$ of the total variability. As a result, the simulation of mean rainfall in the ITCZ and its seasonal migration improves in the higher-resolution case. This suggests that capturing these transient waves and the resultant strong low-level convergence is one of the key ingredients for improving the simulation of precipitation in global coupled climate models.
\end{abstract}

\section{Introduction}

Understanding the variability of the intertropical convergence zone (ITCZ) is a major component of the study of the tropical Atlantic climate system (Xie and Carton 2004). The ITCZ exhibits strong seasonal variability, reaching its maximum northward position $\left(7^{\circ}-\right.$ $9^{\circ} \mathrm{N}$ ) in August-September and migrating to its southernmost location near the equator $\left(3^{\circ} \mathrm{N}-4^{\circ} \mathrm{S}\right)$ in February-April (Chiang et al. 2002). Boreal spring is the season when the ITCZ displays its strongest interannual variability, when the ITCZ can be positioned on

Corresponding author address: Hyodae Seo, Scripps Institution of Oceanography, 9500 Gilman Drive, La Jolla, CA 92093-0224. E-mail: hyseo@ucsd.edu either side of the equator due to the weak meridional sea surface temperature (SST) gradient (Chiang et al. 2002). The anomalous rainfall associated with the variable location and strength of the ITCZ can impose devastating environmental and socioeconomic consequences on the heavily populated regions in northeast Brazil and western Africa (Hastenrath and Heller 1977; Folland et al. 1986; Palmer 1986; Nobre and Shukla 1996).

Although the variability in the ITCZ and the SST in this region can be explained to some extent in terms of the interannual and longer time-scale variability (Zebiak 1993; Nobre and Shukla 1996) in combination with remote forcing from the El Niño-Southern Oscillation (ENSO) through teleconnection mechanisms (Enfield and Mayer 1997; Saravanan and Chang 2000), 
there is no mode of variability stronger than the seasonal cycle in the tropical Atlantic Ocean (Xie and Carton 2004). Furthermore, Davey et al. (2002) reported that most of the state-of-the-art global coupled general circulation models (GCMs) commonly exhibit large biases in the mean climate of tropical regions, particularly in the Atlantic. This indicates that the key processes that determine the mean and annual cycle of the tropical Atlantic climate are still not yet fully understood (Xie and Carton 2004).

The present study focuses on simulating the mean ITCZ in a coupled climate model and sheds light on the importance of synoptic-scale atmospheric processes. The connection of this transient atmospheric feature to the precipitation over northern Africa and the tropical Atlantic Ocean has been extensively studied (Thorncroft et al. 2003 and the references therein). The lowlevel positive meridional potential temperature gradient and the negative midtropospheric meridional potential vorticity gradient during the summertime indicate the existence of the African easterly jet (AEJ; Pytharoulis and Thorncroft 1999). The instability process associated with the baroclinic interaction of these potential temperature and potential vorticity gradients is conducive to the generation of synoptic-scale weather disturbances called African easterly waves (AEWs; Rennick 1976; Reed et al. 1977). Hsieh and Cook (2005) also have pointed out the importance of cumulus convection and the associated release of latent heat within the ITCZ over the African continent in the generation of these atmospheric disturbances. The early analyses of AEWs have revealed the characteristics of these summertime atmospheric disturbances, which have phase speeds of $6-8 \mathrm{~m} \mathrm{~s}^{-1}$ westward with periods of 3-5 days (Carlson 1969; Burpee 1972). These waves contribute to the organized convection (Mekonnen et al. 2006), including mesoscale convective systems (Payne and McGarry 1977), and daily precipitation over western Africa (e.g., Frank 1970; Thorncroft and Hodges 2001; Gu et al. 2004). More importantly, they give birth to tropical cyclones over the Atlantic Ocean (Landsea et al. 1998) and modulate their evolution and movement (Peng et al. 2006). Indeed, Thorncroft and Hodges (2001) have shown a positive correlation between the AEW activity and Atlantic tropical cyclone activity, suggesting that hurricane activity may be influenced by the number of the AEWs leaving the west coast of Africa (see also Avila and Pasch 1992).

In this paper, we examine the effect of these synoptic-scale easterly waves on larger-scale precipitation of the marine ITCZ in two regional coupled model simulations with different atmospheric resolution. We explore how resolution affects the model's ability to cap- ture the horizontal shear and low-level convergence of winds associated with the AEWs, and thus convection and precipitation processes. Analyses reveal that the amplitude of these waves is well simulated on both the coarse $\left(1^{\circ}\right)$ and fine $\left(1 / 4^{\circ}\right)$ atmospheric grids. The cyclonic shear of the wind associated with waves on the finer grid, however, yields stronger near-surface convergence, triggers convection, and thus produces more intense precipitation. The rainfall variability associated with the easterly waves accounts for a significant fraction $(>60 \%-70 \%)$ of the total simulated variance in the marine ITCZ. As a result, simulation of the mean ITCZ improves and the seasonal phasing becomes more realistic.

The paper is organized as follows: in section 2, the description of the models and experimental designs are presented. In section 3, the sensitivity of the AEW-induced atmospheric convergence and precipitation due to model resolution is examined. In section 4, we discuss the impacts on the larger-scale mean climate in the model. Conclusions and discussion follow in section 5 .

\section{Models and experiment setup}

The coupled model used for the present study is the Scripps Coupled Ocean-Atmospheric Regional (SCOAR) model (Seo et al. 2007). It combines two well-known, state-of-the-art regional atmosphere and ocean models using a flux-SST coupling strategy. The atmospheric model is the Experimental Climate Prediction Center (ECPC) Regional Spectral Model (RSM) and the ocean model is the Regional Ocean Modeling System (ROMS).

The RSM, originally developed at the National Centers for Environmental Prediction (NCEP) is described in Juang and Kanamitsu (1994) and Juang et al. (1997). The code was later updated with greater flexibility and much higher efficiency (Kanamitsu et al. 2005). Briefly, it is a limited-area primitive equation atmospheric model with a perturbation method in spectral computation and utilizes a terrain-following sigma coordinate system (28 levels). The model physics are the same as the NCEP global seasonal forecast model (Kanamitsu et al. 2002a) and the NCEP/National Center for Atmospheric Research (NCAR) reanalysis model (Kalnay et al. 1996) except for the parameterization of convection and radiative processes. The parameterization for atmospheric deep convection in the current version of the RSM used in this study is based on relaxed ArakawaSchubert scheme (Arakawa and Schubert 1974; Moorthi and Suarez 1992).

The ROMS solves the incompressible and hydrostatic primitive equations with a free surface on hori- 
zontal curvilinear coordinates and utilizes stretched generalized sigma coordinates to enhance vertical resolution near the sea surface and bathymetry. The details of the model can be found in Haidvogel et al. (2000) and Shchepetkin and McWilliams (2005).

A flux-SST coupler bridges the atmospheric (RSM) and ocean (ROMS) models. The coupler works in a sequential fashion; the RSM and ROMS take turns integrating while exchanging forcing every $24 \mathrm{~h}$. The interacting boundary layer between RSM and ROMS is based on the bulk formula for surface fluxes of momentum and sensible and latent heat adapted from the algorithm of Fairall et al. (1996). Since the grids of the atmosphere and ocean models differ, a simple linear interpolation is used to map the SST and ocean currents to the atmospheric physical space grid and the resultant fluxes to the ocean grid. Care must be taken in choosing the land-sea mask near the coasts because the atmospheric model is spectral and Gibbs' phenomenon can result in unphysical structures in the surface flux forcing fields over the oceanic grid points adjacent to the coast. In each domain, the land-sea mask must be qualitatively optimized to reduce this effect of the mismatch between spectral atmospheric and physical space oceanic models.

The low-wavenumber atmospheric flows from NCEP/Department of Energy (DOE) Reanalysis II (RA2; Kanamitsu et al. 2002b) are specified as a base field over the regional domain of the RSM. The RA2 is available in T62 spectral resolution on a global Gaussian latitude-longitude grid, at roughly $200-\mathrm{km}$ grid size in the tropics. However, the effective resolution in the global spectral analysis is coarser than this estimated grid size, since one needs five to six grid points to accurately represent the smallest wavenumber in the global spectral model (Pielke 1991; Laprise 1992). Thus, wavelengths from circumglobal to $1000 \mathrm{~km}$ are well resolved in the original RA2 model. For downscaling purposes, Kanamaru and Kanamitsu (2007) designed a scale-selective bias correction (SSBC) scheme to reduce the tendency of wavenumbers longer than $1000 \mathrm{~km}$ to drift from the prescribed original RA2 large-scale fields that drive the regional response in RSM. This procedure is invoked in SCOAR, which encourages the large-scale components of AEW events to be similar for both coarse- (e.g., RA2) and higher-resolution (e.g., SCOAR) grids.

The AEWs discussed in this study have a typical wavelength of $2500 \mathrm{~km}$ (Reed et al. 1977) and thus, in SCOAR, they should resemble the waves in the base field from RA2. However, it should be noted that these waves are also substantially influenced by many processes, such as meridional temperature gradient, soil moisture content, monsoonal processes, and the resolved orography (Cook 1999; Mekonnen et al. 2006), which can be modulated differently depending on the SCOAR resolution and its downscaling procedure. Therefore, the differences in the details of these waves in the SCOAR simulations shown in the later sections are, by the experimental design, largely due to changes in SCOAR model resolution.

Here we compare two SCOAR model simulations, where the atmospheric resolution is changed in a domain that covers the tropical Atlantic basin from $30^{\circ} \mathrm{S}$ to $30^{\circ} \mathrm{N}$ and from $70^{\circ} \mathrm{W}$ to $20^{\circ} \mathrm{E}$, including eastern Brazil and western Africa. In the high ocean-low atmosphere (HL) simulation, $14^{\circ}$ resolution is used for the ocean, but low resolution $\left(1^{\circ}\right)$ is used for the atmosphere. In high ocean-high atmosphere $(\mathrm{HH})$, both the ocean and atmospheric models use $1 / 4^{\circ}$ resolution. Hence the only major difference in $\mathrm{HL}$ and $\mathrm{HH}$ is the horizontal resolution in the atmosphere. A minor difference in the two cases is in the altered land-sea mask linking the ocean and atmospheric models. The physical space fields of the atmosphere must be mapped to the oceanic grid (and vice versa) via interpolation, which is sensitive to the details of the land-sea mask near the coastal ocean where large gradients of atmospheric fields often occur.

In a previous study, Seo et al. (2006) used similar SCOAR configurations to show that increasing oceanic resolution alleviates SST biases by $20 \%$, especially in the African upwelling regions. In that study, they compared results from HL and LL simulations, where LL denotes low $1^{\circ}$ resolution in both the ocean and the atmosphere. Despite the improvement in the ocean, the simulation of the mean ITCZ was only marginally improved, likely due to a coarse $1^{\circ}$ horizontal resolution in the atmosphere. The present study is an extension of Seo et al. (2006), focusing on the importance of synoptic-scale processes in the atmosphere in altering the mean precipitation over the Atlantic Ocean.

The initialization and forcing procedures for both cases are as follows: the ROMS ocean was first spun up for $8 \mathrm{yr}$ with climatological atmospheric forcing and climatological oceanic boundary conditions. Then the SCOAR coupled run was launched for $7 \mathrm{yr}$ from 1998 to 2004 with low-wavenumber RA2 atmospheric forcing and climatological oceanic boundary conditions. The 6-yr solution from 1999 to 2004 is analyzed in this study.

In this regional modeling framework, the remote influences on the simulated variability of the ITCZ (Chiang et al. 2002; Xie and Carton 2004) are the same in both SCOAR simulations. Chiang et al. (2002) show that the anomalous Walker circulation affects the pre- 
cipitation over the tropical Atlantic, while the meridional gradient in SST determines the position of the ITCZ. Remote ENSO conditions affect both of these processes: the former through direct atmospheric influence (Dai and Wigley 2000) and the latter via atmospheric teleconnections, which change Northern Hemisphere SST. In the present SCOAR model configurations the large-scale atmospheric and oceanic forcings that drive these two mechanisms are nearly identical. But the regional variability simulated in $\mathrm{HH}$ and $\mathrm{HL}$ for the tropical Atlantic and western Africa may be different in each case, giving rise to differences in variability of SST and the ITCZ. For example, the meridional SST gradient is affected by local ocean-atmosphere-land coupled variability, independent of the remote forcing (Chang et al. 1997; Xie and Carton 2004). Local feedback processes, such as these, are of primary interest in this study.

\section{AEW-induced low-level convergence and precipitation: Sensitivity to model resolution}

African easterly waves are the dominant synopticscale weather disturbances during boreal summer months. These waves originate in eastern Africa (Mekonnen et al. 2006; Kilades et al. 2006; Berry and Thorncroft 2005; Burpee 1972; Carlson 1969) and traverse the tropical Atlantic Ocean. We are interested in how AEW-induced wind shear and convergence lead to large precipitation events within the marine ITCZ.

To illustrate the summertime background environments that foster the generation of the disturbances, Fig. 1 compares the large-scale features between the model simulations and the RA2 during the summertime [July-September (JAS)]. Figures 1a-c show wind fields at $700 \mathrm{hPa}$ (the jet level) from the model simulations and RA2 over northern Africa and the eastern Atlantic Ocean. In RA2, the core of the AEJ at this level is identified as a maximum of the easterly wind present on the west coast of Africa at $15^{\circ} \mathrm{N}, 15^{\circ} \mathrm{W}$, where wind speed reaches $10 \mathrm{~m} \mathrm{~s}^{-1}$. The width of the jet is about $10^{\circ}$ in latitude and the axis of the jet extends eastward over the continent with an apparent southward shift (Cook 1999). These observed wind structures are well reproduced in both regional simulations, although the models produce stronger jets than RA2. The spatial patterns of the jet are qualitatively similar in both simulations, although the jet in $\mathrm{HH}$ is slightly stronger than HL at the core over western Africa. The meridional gradient of vorticity at the jet level (Figs. 1d-f) and the near-surface potential temperature (Figs. 1g,h) are largely similar in $\mathrm{HH}$ and $\mathrm{HL}$, indicating that barotropic and baroclinic instability conditions that support the formation of the jet (Charney and Stern 1962; Burpee 1972) are similar for both $1^{\circ}$ and $1 / 4^{\circ}$ atmospheric resolution. The simulated positive $925-\mathrm{hPa}$ potential temperature gradient over northern Africa (Figs. 1g,h) compares well with RA2 (Fig. 1i) and the previous study (e.g., Pytharoulis and Thorncroft 1999). The model relative vorticity on the $700-\mathrm{hPa}$ surface (Figs. $1 \mathrm{~d}, \mathrm{e})$ is also qualitatively similar to the observed potential vorticity on the $315-\mathrm{K}$ isentropic surface (Fig. 4 of Pytharoulis and Thorncroft 1999), exhibiting a negative vorticity gradient near and north of the jet and a positive vorticity gradient south of the jet.

Figure 2 shows the variance of summertime synopticscale (2-6 day) 850-hPa meridional winds for each simulated year over the Atlantic Ocean where the variance is large. The 2-6-day bandpass filtering to highlight the AEW signals in meridional wind field was previously used by Albignat and Reed (1980) and Mekonnen et al. (2006). Except for the summer of 1999 when they are nearly equally strong, AEW variance over the ocean is stronger in $\mathrm{HH}$ than in $\mathrm{HL}$, with mean variance being $20 \%$ larger in the higher-resolution case. The standard deviation of the meridional winds is therefore only slightly $(\sim 4 \%-5 \%)$ stronger in $\mathrm{HH}$ than HL. An F test indicates that the difference in variance in $\mathrm{HH}$ and $\mathrm{HL}$ is not statistically different (at $95 \%$ significance level). Thus both higher- and coarser-resolution simulations yield statistically similar amplitudes of the AEWs over the tropical Atlantic Ocean. The strikingly different features between the two simulations that emerge from the similar environments associated with the waves are the associated near-surface convergence and the precipitation, which is discussed later.

To investigate and compare the details of the simulated wave structure and its propagation, Fig. 3 presents Hovmöller diagrams of 2-6 bandpass-filtered $850-\mathrm{hPa}$ winds for JAS of 2003 when the difference between $\mathrm{HH}$ and HL was largest (Fig. 2). The simulated AEWs from HH (Fig. 3a) and HL (Fig. 3b) exhibit wave characteristics consistent with the observed estimates by the synoptic map analysis of Carlson (1969), the compositing study of Reed et al. (1977), and the synoptic map analysis of Burpee (1972), all of which found typical wavelengths of $2000-4000 \mathrm{~km}$, periods of 3.2-3.5 days, and phase speeds of $\sim 8 \mathrm{~m} \mathrm{~s}^{-1}$. The simulated phase of the waves is similar between the model simulations and also with the observations.

These large amplitude waves propagate well beyond the eastern Atlantic, traversing the Atlantic Ocean and reaching the Caribbean and western boundary of the model domain. Previous studies have reported that they often propagate beyond the Caribbean across Central America into the eastern Pacific basin (Frank 

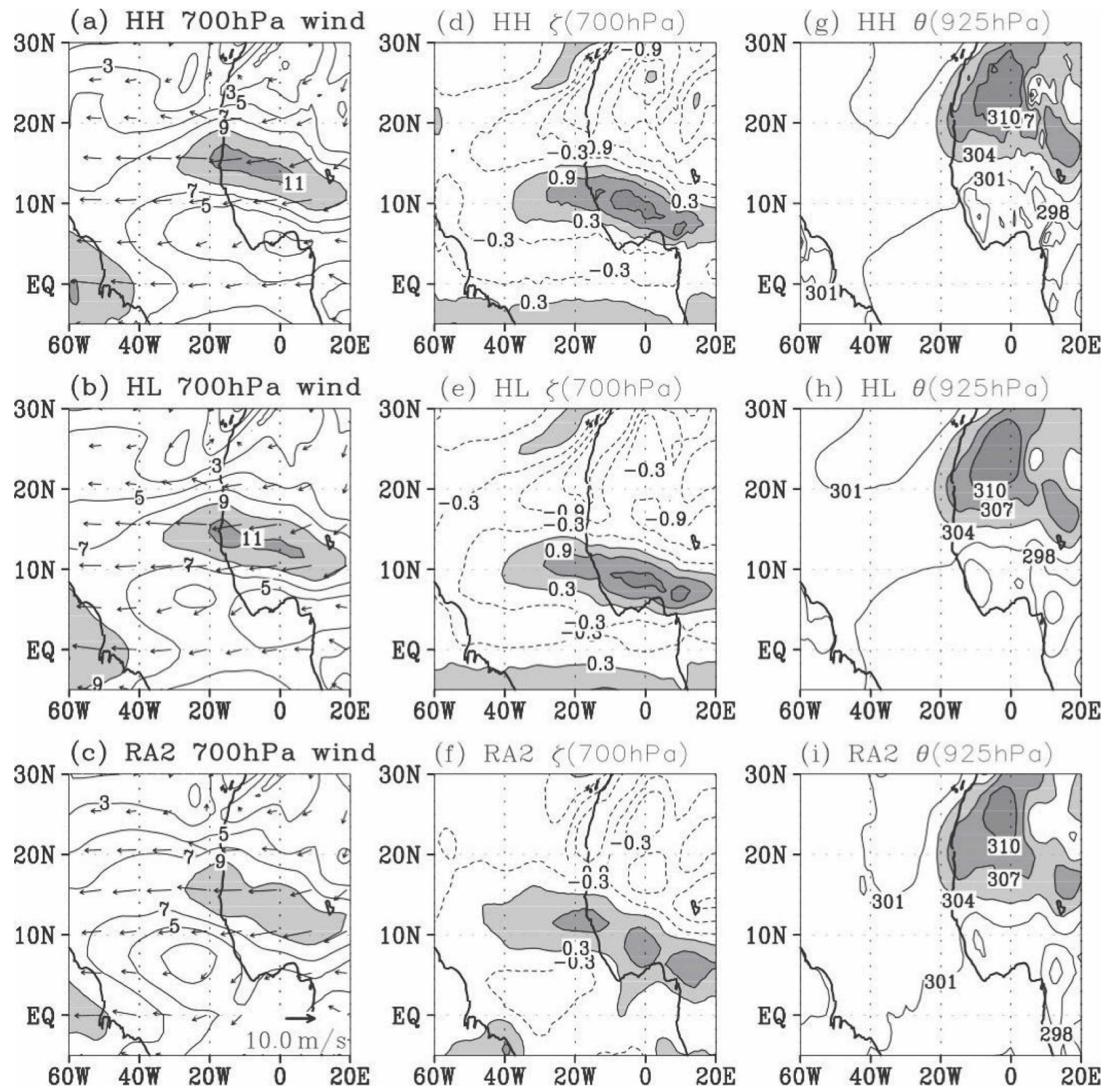

FIG. 1. Six-year summertime (JAS) mean (a)-(c) wind velocity at $700 \mathrm{hPa}$ (shaded when $>9 \mathrm{~m} \mathrm{~s}^{-1}$ ), (d)-(f) 700-hPa relative vorticity (shaded when $>0.3 \mathrm{~s}^{-1}$ ), and (g)-(i) 925-hPa potential temperature (shaded when $>304 \mathrm{~K}$ ). (top) HH, (middle) HL, and (bottom) RA2. (top) $\mathrm{HH}$ and (bottom) RA2 are interpolated to the grids on HL.

1970), where they contribute to tropical cyclogenesis (Avila and Pasch 1992). Over the tropical Atlantic Ocean, strong cyclonic shear of the horizontal winds associated with the large amplitude of these waves is accompanied by localized intense precipitation (contours overlaid in Fig. 3a), implying a tight connection between wind shear generated by AEWs and strong precipitation (Thorncroft and Hodges 2001). Early analyses by Frank (1970) and Burpee (1972) concluded that the easterly waves account for about half of the tropical cyclones in the Atlantic Ocean. Figure 3a suggests that the heavy precipitation events in this model are associated with simulated tropical cyclones, which were formed within the environment favored by the easterly waves in the model. On the other hand, despite the reasonably well-simulated AEWs in HL, there are few heavy precipitation events compared to those that occur with the strong wind shear in $\mathrm{HH}$ (the contours of 


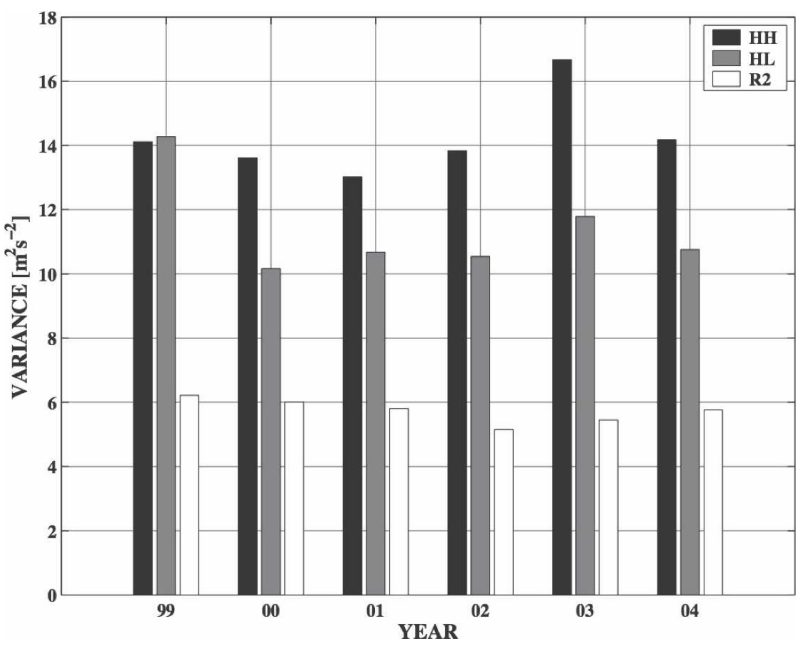

FIG. 2. Variance of 2-6-day filtered $850-\mathrm{hPa}$ meridional wind speed averaged over $5^{\circ}-15^{\circ} \mathrm{N}$ and $55^{\circ}-15^{\circ} \mathrm{W}$ and for summer months (JAS) for 1999-2004 for HH (black), HL (gray), and RA2 (white). The mean variance in HH, HL, and RA2 is $14.2,11.3$, and $5.7 \mathrm{~m}^{2} \mathrm{~s}^{-2}$, respectively.

Fig. 3b). [Note that RA2 does not assimilate precipitation (Kanamitsu et al. 2002a) so that individual precipitation events may or may not correspond to observations.]

The heavy precipitation events in $\mathrm{HH}$ in the region of high cyclonic shear in the easterly waves are closely related to the markedly enhanced near-surface convergence. Figure 4 presents the same plot of meridional winds as in Fig. 3, but overlaid with the 2-6-day filtered convergence of the $10-\mathrm{m}$ winds diagnosed from the model and RA2. First of all, the coarse grid of RA2 leads to virtually zero near-surface convergence, which does not allow comparison with the model results. In $\mathrm{HH}$, strong convergence occurs within the region of high shear of easterly waves, which is in phase with the heavy precipitation seen in Fig. 3a. The in-phase relationship also occurs in HL, although the estimated convergence is generally weaker, producing weaker precipitation (in Fig. 3b).

The association among the cyclonic wind shear of the easterly waves, near-surface convergence, and the enhanced precipitation events shown in Figs. 3 and 4 can be better illustrated in the selected yet representative example in Fig. 5. It shows the two-day averaged fields of model rainfall, convergence of $10-\mathrm{m}$ winds, and outgoing longwave radiation (OLR) during 31 August-1 September 2003, a period of strong AEW activity and intense precipitation (Fig. 3). Note that this time period corresponds to the development of Hurricane Fabian in observations in this region of the tropical Atlantic as provided by the National Hurricane Center. Model

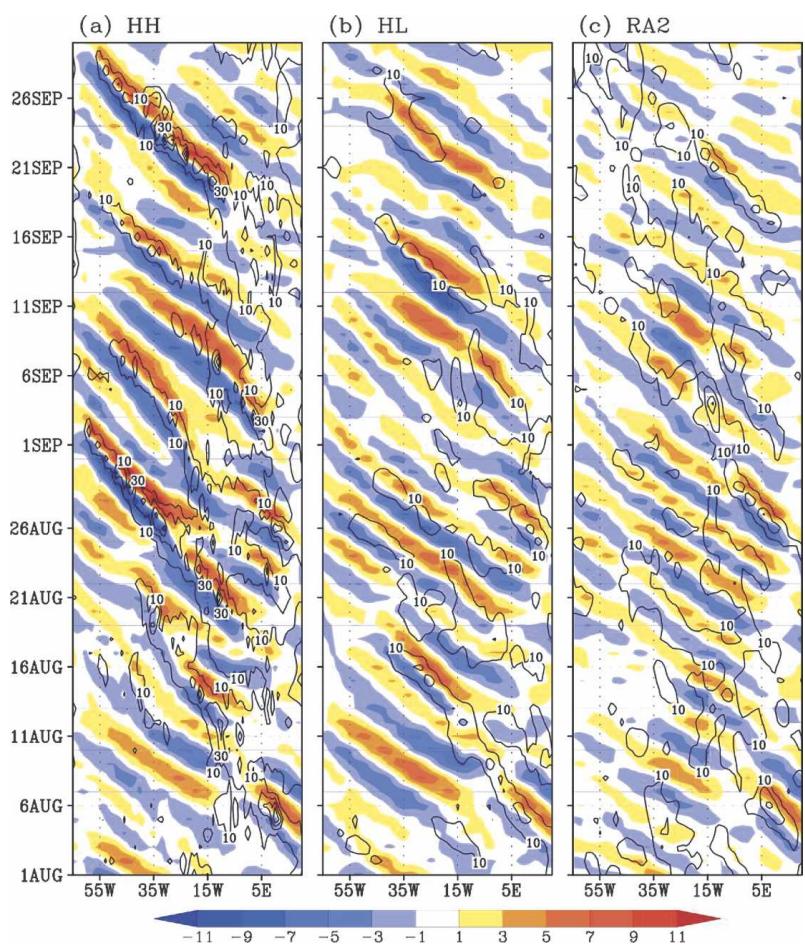

FIG. 3. Hovmöller diagrams of 2-6-day filtered meridional wind speed $\left(\mathrm{m} \mathrm{s}^{-1}\right)$ at $850 \mathrm{hPa}$ averaged between $5^{\circ}$ and $15^{\circ} \mathrm{N}$ for August-September 2003 from (a) HH, (b) HL, and (c) RA2. Overlaid on the winds are the contours of unfiltered rainfall $(\mathrm{mm}$ day $^{-1}$, contours $=10,30$, and $50 \mathrm{~mm} \mathrm{day}^{-1}$ ) for the same period. [Note that RA2 does not assimilate precipitation (Kanamitsu et al. 2002b) so that individual precipitation events may or may not correspond to observations.]

tropical storms do not necessarily follow observations closely, however, since the path and intensity of model mesoscale disturbances are free to evolve without constraint due to dynamical instability processes, which are sensitive to initial conditions.

During this particular period, the large wave amplitudes shown in Figs. $3 a$ and $3 b$ are due to tropical cyclones (or depressions) located near $13^{\circ} \mathrm{N}, 50^{\circ} \mathrm{W}$ and $7^{\circ} \mathrm{N}, 20^{\circ} \mathrm{W}$ in $\mathrm{HH}$ and HL. The cyclone simulated in $\mathrm{HH}$ produces massive precipitation of more than 200 $\mathrm{mm}$ day $^{-1}$ and is associated with a local minimum of OLR, which indicates that precipitation occurs through a convective process. This convective precipitation in the cyclone is in turn associated with the strong lowlevel convergence that exceeds $6 \times 10^{-5} \mathrm{~s}^{-1}$ at the core. In HL, on the other hand, weaker convergence of less than $3 \times 10^{-5} \mathrm{~s}^{-1}$ causes weaker convection and thus less rain of only $30 \mathrm{~mm}$ day $^{-1}$.

Heavy rainfall exceeding $200 \mathrm{~mm}$ day $^{-1}$ captured by $\mathrm{HH}$ is an observed phenomenon. Lonfat et al. (2004), for example, reported that a maximum rainfall rate of $288 \mathrm{~mm} \mathrm{day}^{-1}$ is observed for category $3-5$ systems of 


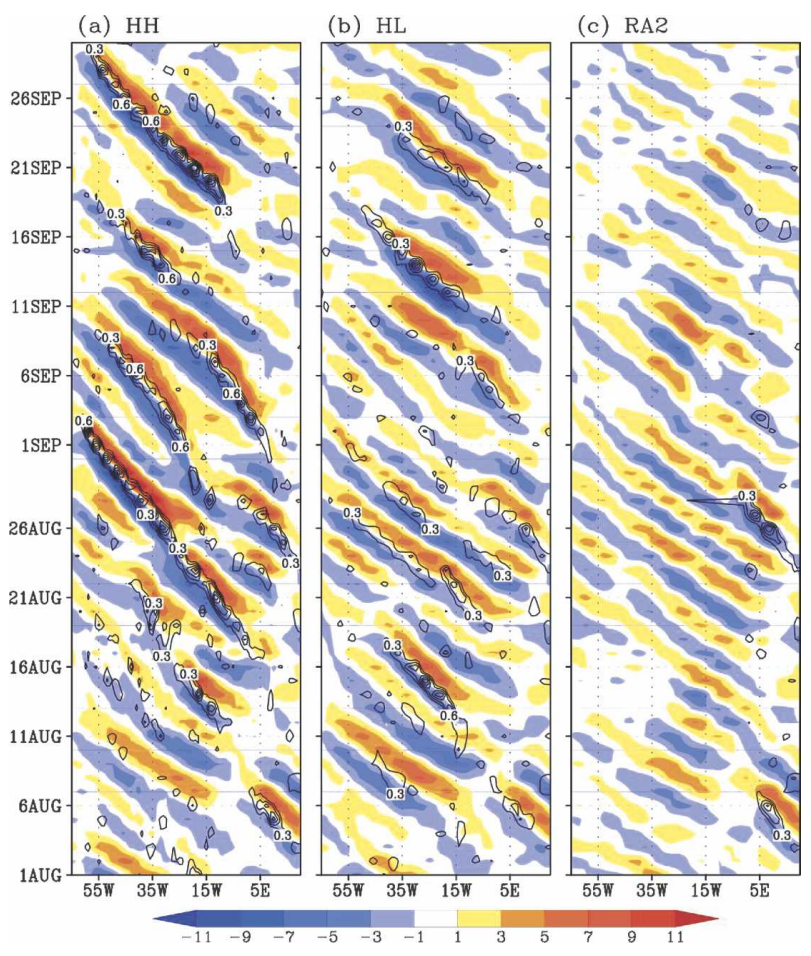

FIG. 4. Same as in Fig. 3, but overlaid with the contours of 2-6-day filtered near-surface convergence $\left(10^{-5} \mathrm{~s}^{-1}\right)$, which was computed from $10-\mathrm{m}$ winds. Only convergence is contoured $(0.3$ interval with the zero contours omitted). Note the coarse grid of RA2 leads to generally zero near-surface convergence, which does not allow comparison with the model results.

hurricanes using the Tropical Rainfall Measuring Mission (TRMM) Microwave Imager rain estimates. Observations of rainfall rate measured from moored buoys agree with this as well. Figure 6a shows time series of rainfall measured at the Pilot Research Moored Array in the Tropical Atlantic (PIRATA) buoy moored at $4^{\circ} \mathrm{N}-38^{\circ} \mathrm{W}$ and from the model grid at the mooring site. In both models and observations, the variability of rainfall is markedly larger than its mean. The standard deviation (std) of rainfall in the observations is roughly 4 times greater than its mean, while in HH (HL) the std is 2.5 (1.7) times larger than its mean. The strongest peak in the observations at this particular site during this period reaches $914 \mathrm{~mm}$ day $^{-1}$. Statistically, the means of $\mathrm{HH}$ and $\mathrm{HL}$ are both consistent with PIRATA, but the variability in $\mathrm{HH}$ is clearly more realistic than in HL. The map of std of rainfall (not shown) reveals that, in a large area around this mooring site, the std of $\mathrm{HH}$ rainfall is greater than $25 \mathrm{~mm}_{\text {day }}{ }^{-1}$, while HL has everywhere a std less than $10 \mathrm{~mm}_{\text {day }}{ }^{-1}$. Thus, the chosen mooring site is a typical location within the ITCZ where variability in rainfall well exceeds its mean. The probability distribution functions
(PDFs) of observed rainfall (Fig. 6b) confirms that several peaks produce extremely high precipitation in the observations. Although $\mathrm{HH}$ rainfall does not display peaks as strong as in the observations, the extreme cases shown in $\mathrm{HH}$ compares better with the observations. This indicates that increasing model resolution can enhance heavy precipitation events, which skew the rainfall distributions toward longer tails.

Biasutti et al. (2006) have shown that most of the atmospheric general circulation models (AGCMs) underestimate the high-frequency variability of the rainfall within the marine ITCZ and thus exhibit a reduced range in daily precipitation there. The observed rainfall distribution, on the other hand, extends to higher rainfall values with shorter decorrelation time scales $(\sim 1$ day). Figure 6 indicates that HL resembles the typical case of these AGCMs, while HH emulates the observed distribution of daily precipitation.

The heavy precipitation events are closely related to the convergence fields (Fig. 4), which are better resolved on the higher-resolution atmospheric grid. This relation is illustrated in Fig. 7. It shows PDFs of convergence for the 10-m wind computed from the models in comparison with the estimate from the Quick Scatterometer (QuikSCAT) winds over 2000-04, averaged over the ITCZ $\left(2^{\circ}-7^{\circ} \mathrm{N}\right.$ and $\left.40^{\circ}-30^{\circ} \mathrm{W}\right)$. Both model runs exhibit the slight skewness toward convergence as in the observations, implying large-scale convergence within the ITCZ. Yet, convergences greater than $6 \times$ $10^{-5} \mathrm{~s}^{-1}$ are found only in the observations and in $\mathrm{HH}$. On the other hand, the convergence does not exceed $6 \times 10^{-5} \mathrm{~s}^{-1}$ in $\mathrm{HL}$ for any event during this 5 -yr period in this region. The propensity for even higher convergence is observable in QuikSCAT winds, and $\mathrm{HH}$ is clearly better than HL when compared with the QuikSCAT.

Easterly waves are large-scale atmospheric processes (wavelengths of 2000-4000 km) and thus, compared to the $1 / 4^{\circ}$ resolution in $\mathrm{HH}$, the $1^{\circ}$ atmospheric resolution should be sufficient to resolve the wave activity reasonably well. Indeed, the simulated 6-yr mean variances of the wind were not statistically different. Furthermore, Figs. 3 and 4 suggest that the related cyclonic wind shear is well simulated on both grids. However, compared to the $1^{\circ}$ grid, it rains more, and with a far more realistic distribution, on the $14^{\circ}$ grid. The lack of rain in HL despite the reasonably well-resolved AEWs implies that wind convergence and subsequent convection are important processes to produce a realistic mean precipitation pattern. At $1 / 4^{\circ}$ resolution, we approach the horizontal scales of convection and are nearly able to resolve the observed low-level convergence (Fig. 7).

This result can be anticipated from the idealized 
(a) HH Rain Rate

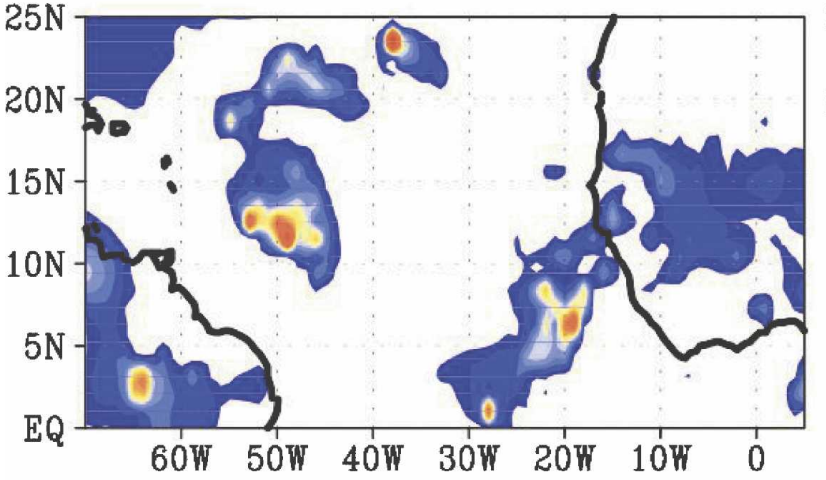

(b) HL Rain Rate

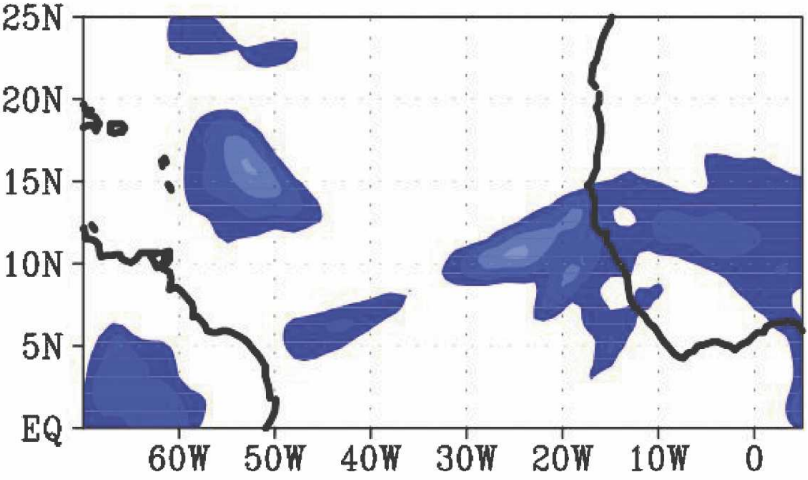

\begin{tabular}{lllllllllllll}
\hline 5 & 10 & 20 & 30 & 40 & 50 & 60 & 70 & 80 & 90 & 100 & 150 & 200
\end{tabular}

(c) $\mathrm{HH}$ Convergence

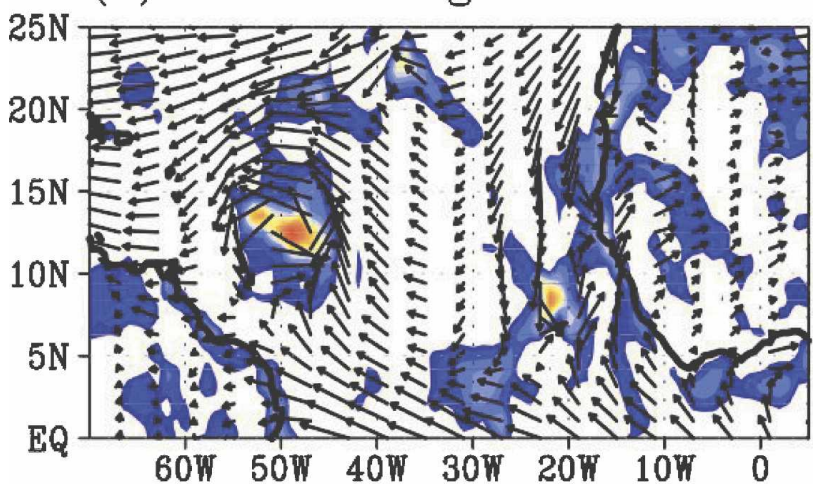

(d) HL Convergence

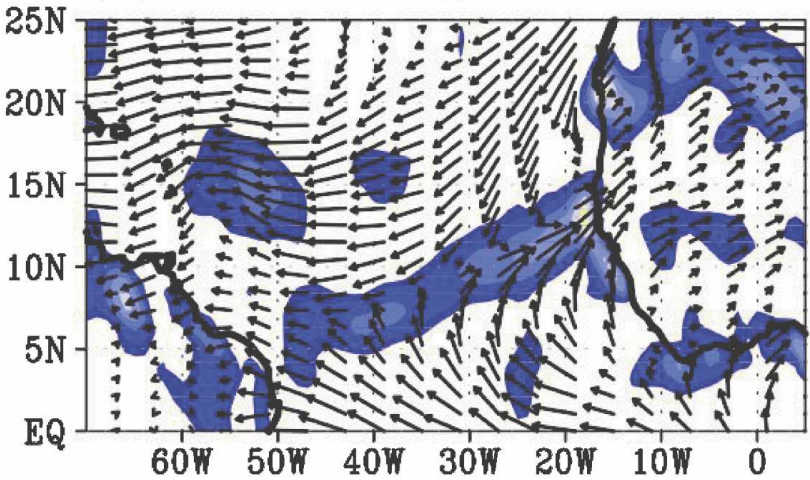

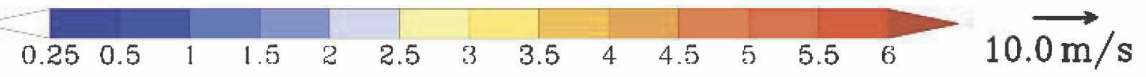

(e) HH OLR

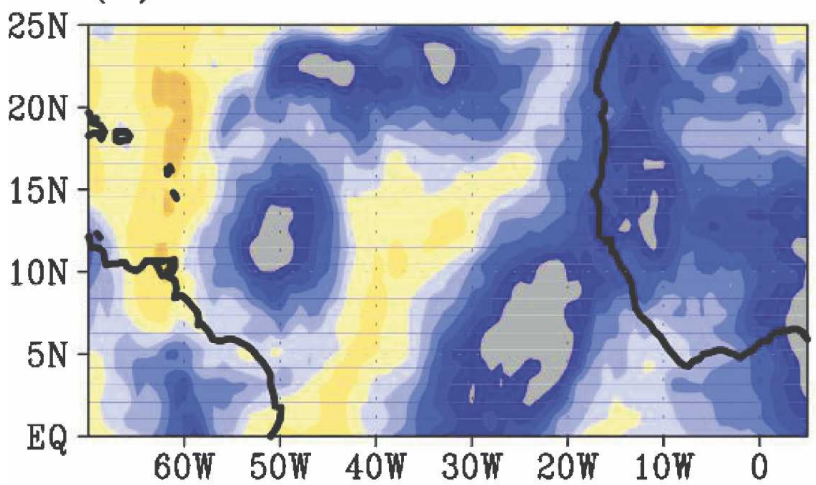

(f) HL OLR

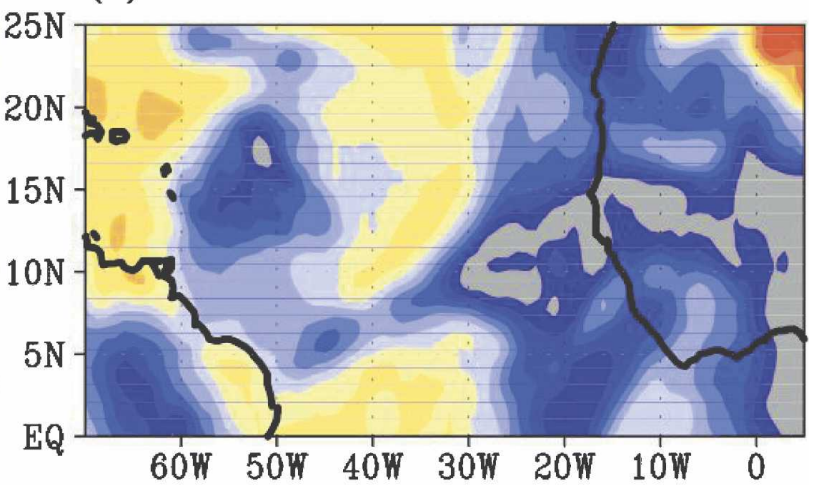

\section{$\begin{array}{lllllllllll}220 & 230 & 240 & 250 & 260 & 270 & 280 & 290 & 300 & 310 & 320\end{array}$}

FIG. 5. Two-day averages (31 Aug-1 Sep 2003) of (a), (b) rainfall (mm day $\left.{ }^{-1}\right),(\mathrm{c}),(\mathrm{d})$ near-surface convergence $\left(10^{-5} \mathrm{~s}^{-1}\right)$ of $10-\mathrm{m}$ winds and wind velocity ( $\mathrm{m} \mathrm{s}^{-1}$ ), and (e), (f) OLR ( $\mathrm{W} \mathrm{m}^{-2}$ ) from (left) $\mathrm{HH}$ and (right) HL. Only convergence is plotted in (c) and (d) for clarity. OLR less than $220 \mathrm{~W} \mathrm{~m}^{-2}$ in (e) and (f) is plotted in gray and represents strong atmospheric convection. 
(a)
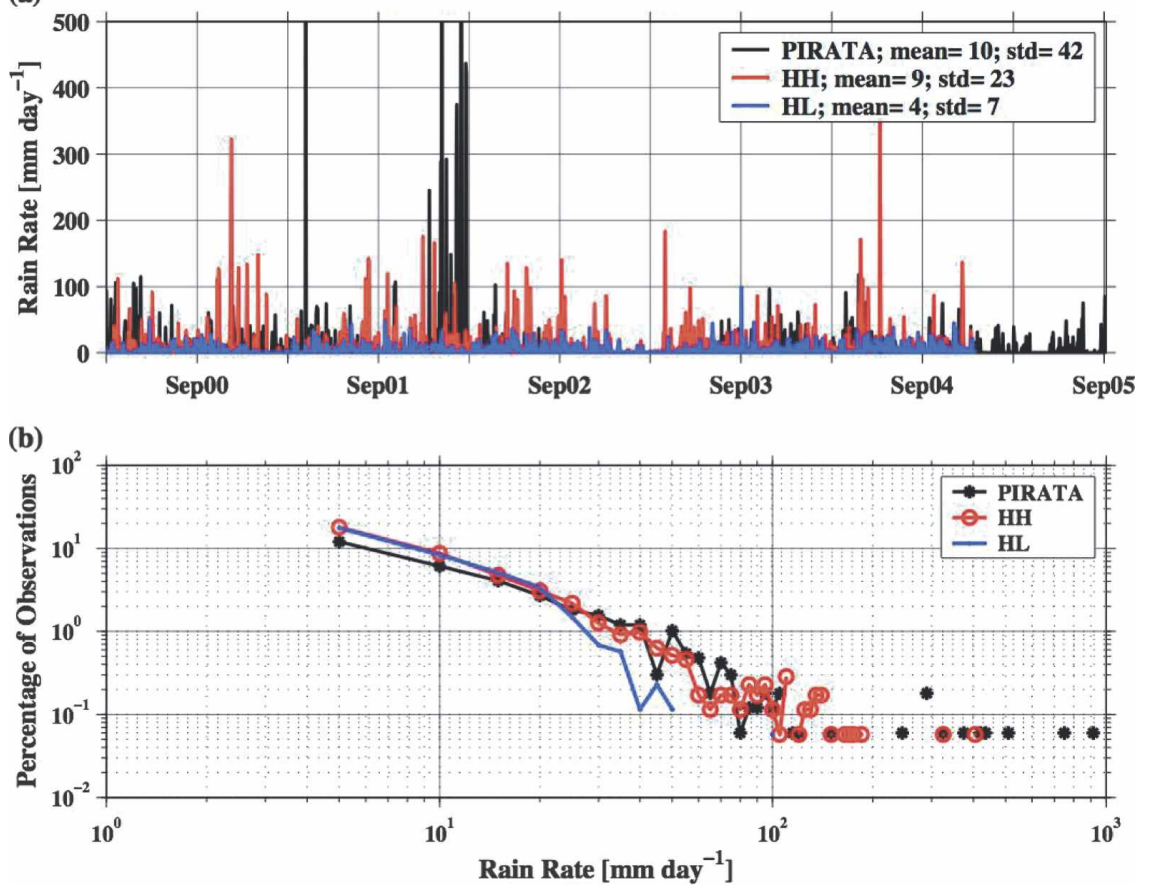

FIG. 6. (a) Time series of rainfall measured from the PIRATA mooring site at $4^{\circ} \mathrm{N}, 38^{\circ} \mathrm{W}$ from March 2000 to September 2005 (black line). There is a gap in the observations from mid-August 2002 to late August 2003, and no interpolation has been done in computing the mean and std dev. Model rainfall is shown in red (HH) and blue (HL) at the nearest grid point to the mooring site. Mean and std dev are shown in the upper-right corner of the plot. For the purpose of display, the $y$ axis is limited to $500 \mathrm{~mm}_{\text {day }}{ }^{-1}$. There are three occasions in the observations where the rainfall exceeds the limit of this plot. The precipitation amounts $(\mathrm{mm}$ day $^{-1}$ ) on these 3 days are 508 on 24 Apr 2000, 751 on 22 Jan 2001, and 914 on 2 Mar 2001. (b) Same as in (a), but for the probability distribution functions of the observed and simulated precipitation rates (shown with log scales).

study of Pauluis and Garner (2006) on the impacts of the horizontal resolution on the statistics of the atmospheric convection. They demonstrate a close connection between the horizontal resolution of the cloudresolving model and the statistical properties of the deep convective towers. They find a significant improvement in the simulation of vertical velocity and convection (and thus perhaps the low-level convergence) when they transit from coarse $50-\mathrm{km}$ to finer 16-km horizontal resolutions.

The close connection between convergence and the convection is supported by the recent study of Biasutti et al. (2006). They show the importance of dynamic lifting in the deep convection of the marine ITCZ, which allows the observed maximum ITCZ precipitation to be positioned over the region of the maximum near-surface convergence rather than the maximum SST. Most of the AGCMs, on the other hand, are shown to be overly sensitive to the thermodynamic convective available potential energy over warm SST, yielding a tendency to locate the maximum ITCZ rainfall over the local maximum SST.

\section{Impacts on the larger-scale mean precipitation and SST}

\section{a. Mean and seasonal cycle of the ITCZ}

Synoptic precipitation events associated with the easterly wave convergence and convection contribute a significant fraction of the total rainfall variability. Figure 8 shows the ratio of the variance of 2-6-day filtered rainfalls to the total variance. Within the marine ITCZ, synoptic-scale precipitation accounts for $40 \%-60 \%$ of the total variance in HL. This high ratio in HL is striking, indicating that more than half of the total rainfall variability originates from the synoptic scales. The RA2 has a similar percentage of the variance associated with synoptic events (Fig. 8c), suggesting that this $40 \%-60 \%$ contribution to rainfall variability in the marine ITCZ may be an upper limit from the synoptic-scale variabil- 


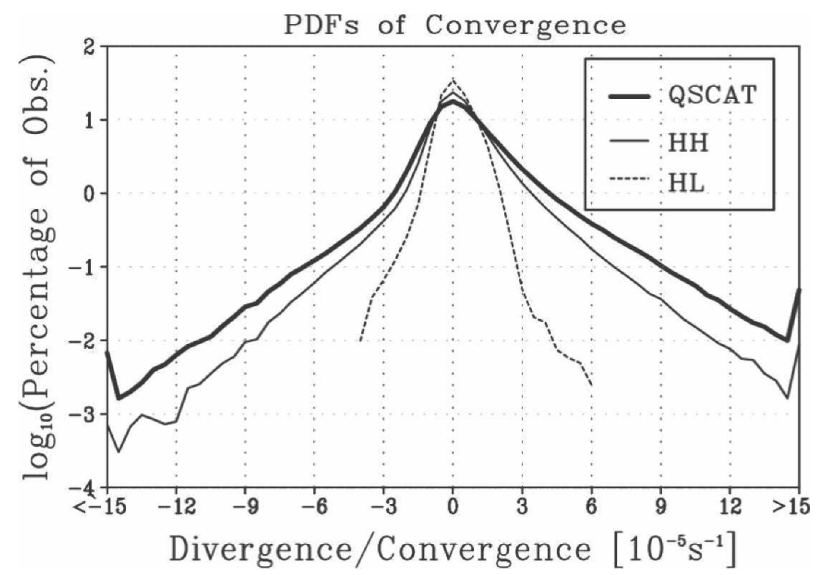

FIG. 7. Probability distribution functions of $10-\mathrm{m}$ wind convergence from the QuikSCAT (thick solid line), $\mathrm{HH}$ (thin solid line), and HL (thin dashed line) from 2000 to 2004 over $2^{\circ}-7^{\circ} \mathrm{N}$ and $40^{\circ}-30^{\circ} \mathrm{W}$. Note the $y$ axis is shown in logarithmic scale to highlight the difference at the higher ends. The positive (negative) values are convergence (divergence).

ity on the coarser grids. In $\mathrm{HH}$, however, the ratio rises to more than $60 \%-70 \%$, suggesting that a substantial fraction of the total rainfall variability is indeed determined by the synoptic-scale heavy rainfall events associated with the easterly waves.

The fact that a significant fraction of rainfall variance is explained by synoptic-scale variability implies that there will be a net contribution to the larger-scale mean rainfall in the model. Figure 9 shows the 6-yr mean precipitation from 1999 to 2004 from the model in comparison with the observational estimates from the Global Precipitation Climatology Project (GPCP; Xie and Arkin 1997) for the corresponding period. Precipitation from both observations and the model shows the ITCZ (as described in Chiang et al. 2002) as a zonally tilted (northeast-southwest) structure over the open ocean with maximum rainfall between the equator and $10^{\circ} \mathrm{N}$. Although the $\mathrm{HH}$ model tends to produce more rain within the marine ITCZ than the observations, the figure demonstrates that the rainfall simulation in $\mathrm{HH}$ is improved compared to HL. Precipitation over the open ocean in $\mathrm{HH}$ is about $9 \mathrm{~mm}$ day $^{-1}$, much closer to the observed rainfall of about $8 \mathrm{~mm} \mathrm{day}{ }^{-1}$. On the other hand, rainfall in HL is only $4 \mathrm{~mm}_{\text {day }}{ }^{-1}$.

Figure 10 illustrates the seasonal variation of the location of maximum precipitation in the model and observations, representing the seasonal migration of the ITCZ. Generally, the location of the ITCZ is well reproduced in the model during most of the year except for the boreal spring season. During boreal spring months, from February to May, the ITCZ in HL crosses the equator into the Southern Hemisphere, while the (a)

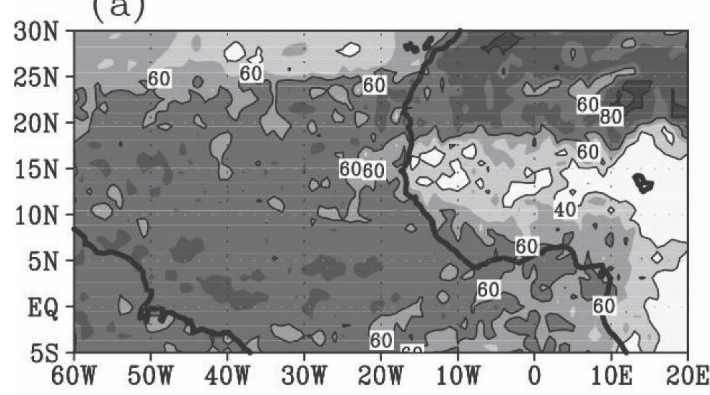

(b)

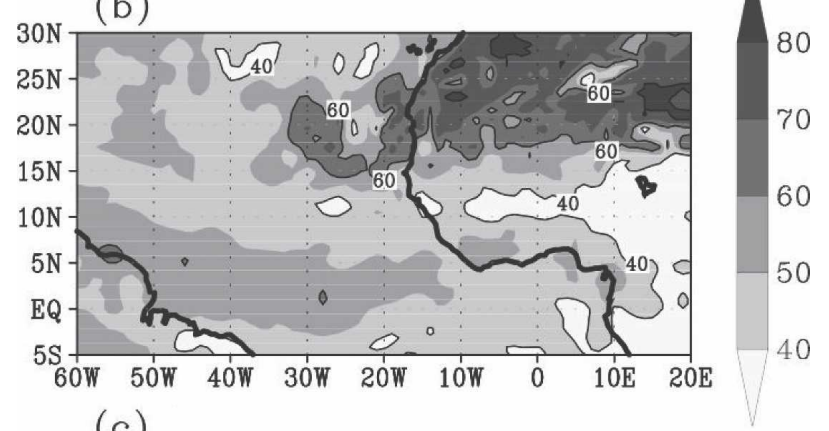

(c)

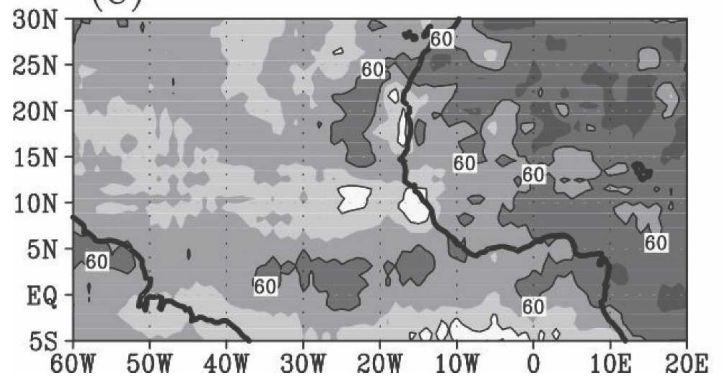

FIG. 8. Ratio (\%) of variance of 2-6-day bandpass-filtered rainfall to the variance of the total rainfall from (a) $\mathrm{HH}$, (b) $\mathrm{HL}$, and (c) RA2 averaged from 1999 to 2004. Contours shown are $50 \%$, $60 \%$, and $70 \%$. The variances are computed for all seasons.

ITCZ in HH stays north of the equator throughout the year, which is consistent with the observations (Chiang et al. 2002). It is clear that not only the mean rainfall but also the seasonal cycle of the ITCZ is better simulated in $\mathrm{HH}$ than in HL.

\section{b. Large-scale SST distribution}

This section investigates the role of large-scale mean SST and its relation to the improved ITCZ simulation. Figure 11a shows the 6-yr mean SST for $\mathrm{HH}$, and the mean difference with HL (HH minus HL) is presented in Fig. 11b. Also shown are (HH minus HL) difference maps of 6-yr mean surface winds, net surface heat flux, latent surface heat flux, and surface radiative flux. The change in SST when increasing the resolution (Fig. 11b) shows a notable basin-scale open-ocean cooling of $\sim 0.5^{\circ} \mathrm{C}$ in the extratropics in both hemispheres, little 

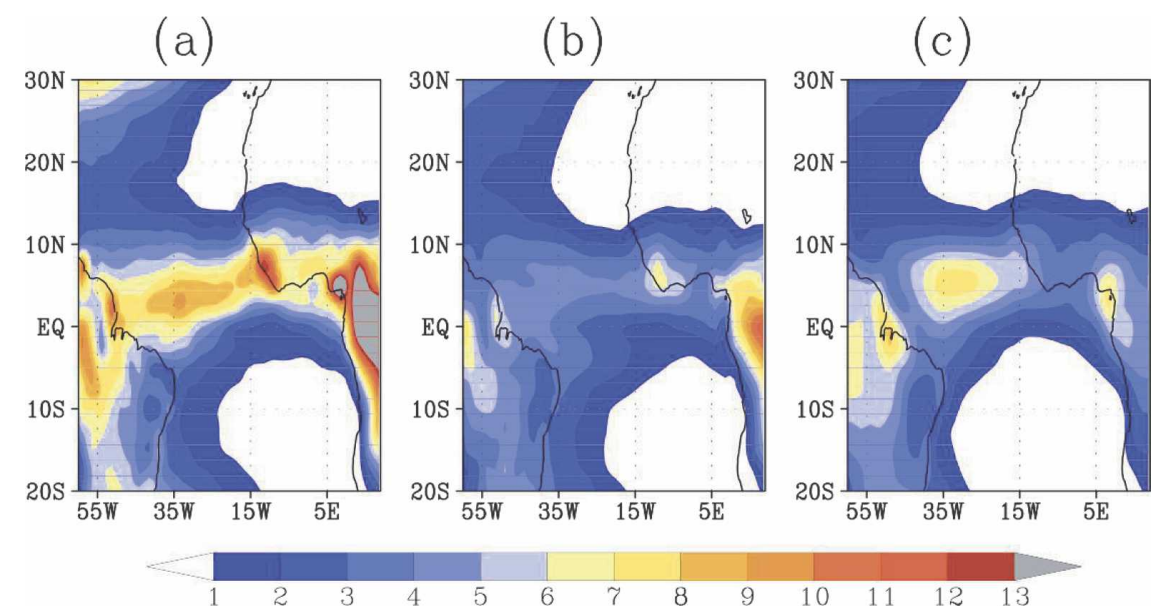

FIG. 9. Six-year (1999-2004) mean rainfall (mm day ${ }^{-1}$ ) from model: (a) HH, (b) HL, and (c) the observations from the GPCP. The model precipitation in (a) and (b) is regridded to the GPCP grids at $2.5^{\circ} \times 2.5^{\circ}$. Precipitation $>13 \mathrm{~mm}^{\text {day }}{ }^{-1}$ is shaded in gray.

change near the equator $\left(5^{\circ} \mathrm{S}-5^{\circ} \mathrm{N}\right)$, and coastal warming (up to $2^{\circ} \mathrm{C}$ ) along the west coast of Africa. The cooling in the extratropics and warming along the coast are both damped by the net surface heat flux (Fig. 11d). On the other hand, SST does not change along the equator, implying the presence of an altered oceanic heat flux at the ocean surface, which balances the thermodynamic cooling. The altered total surface heat flux along the equator is a result of both evaporative cooling by enhanced southeasterly winds (Fig. 11c) and radiative cooling by increased cloudiness (not shown). In $\mathrm{HH}$, both hemispheres have enhanced trade winds that support the large-scale convergence into the ITCZ, which is significantly stronger even though the mean position of the ITCZ remains nearly the same in $\mathrm{HH}$ and HL (Fig. 9).

Figure 12 shows the seasonal cycles of monthly averaged SST in the extratropics for both hemispheres in the regions where the SST was colder in HH. Both in the Northern and Southern Hemispheres, the SSTs in $\mathrm{HH}$ are persistently colder than HL throughout the annual cycle. The seasonal cycle of the position of ITCZ (Fig. 10) is sensitive to the seasonal variability of the meridional (interhemispheric) gradient of SST through the modulation of meridional surface pressure gradient and the near-surface winds (Hastenrath and Greischar 1993). The seasonal cycle of the anomalous meridional SST gradient is computed as the difference in anomalous SST between the northern and southern regions defined in Figs. 12a and 12b. Chiang et al. (2002) defined the tropical Atlantic gradient index in a similar way (albeit using zonally integrated SST instead of using a box) to describe the relation among the meridional SST gradient, the near-surface winds, and the precipitation in the ITCZ. Figure $12 \mathrm{c}$ shows that the seasonal cycles of the simulated meridional SST gradients are almost indistinguishable, albeit weaker than the observed estimate. The gradients look similar in the model simulations because the open-ocean SST cooled by roughly the same amount in both hemispheres in $\mathrm{HH}$.

The debate still continues about whether the meridional SST gradient and the large-scale convergence determine the rain in the ITCZ or whether the wind convergence is determined by midtropospheric heating and hence the rainfall in the ITCZ. Gill (1980) argues for the latter, whereas Lindzen and Nigam (1987) favor the former. Figure 11 suggests that Gill (1980) is more relevant in the current model because the meridional SST gradient did not change in the simulations; this implies that the enhanced southerlies in $\mathrm{HH}$ are forced by the larger-scale, stronger ITCZ.

Enhanced southerlies across the equator will have

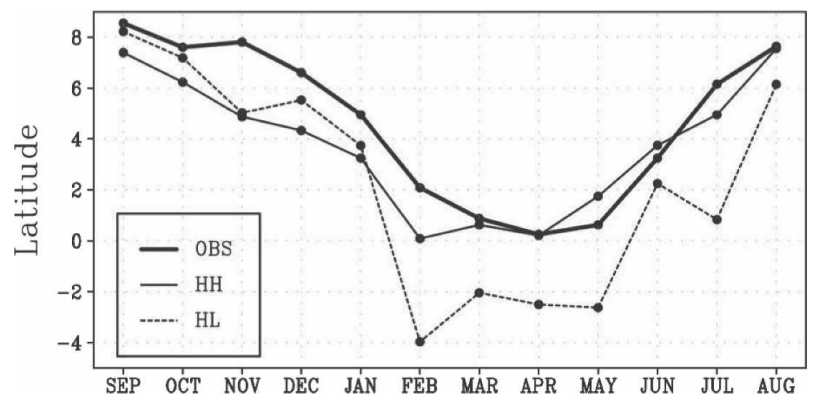

FIG. 10. The seasonal variation of latitude of the maximum precipitation averaged between $50^{\circ}$ and $20^{\circ} \mathrm{W}$ from the $6-\mathrm{yr}$ (1999-2004) monthly averages for the GPCP precipitation (thick solid), HH (thin solid line), and HL (thin dashed line). 
(a) Mean SST: HH

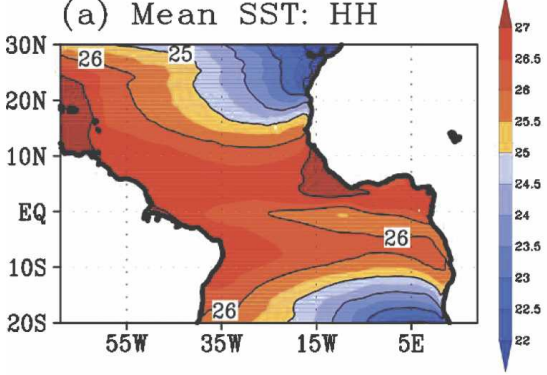

(c) Mean Wind: $\mathrm{HH}-\mathrm{HL}$

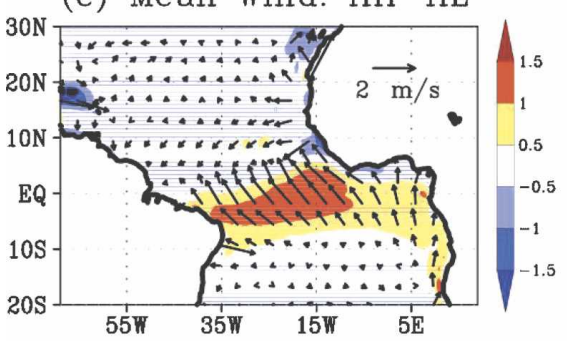

(e) Mean Qlh: HH-HL

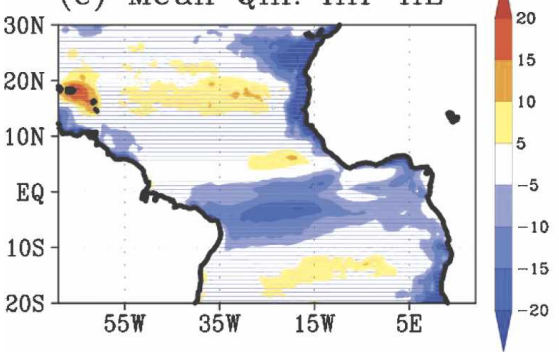

(b) Mean SST: HH-HL

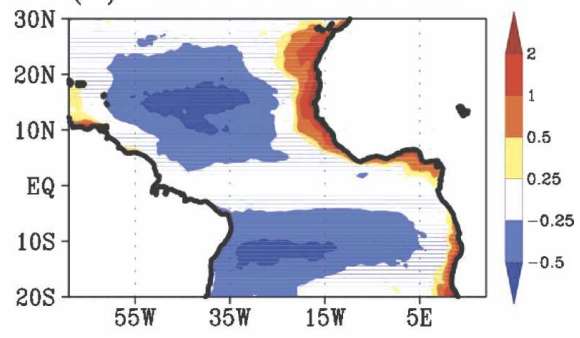

(d) Mean Qnet: $\mathrm{HH}-\mathrm{HL}$

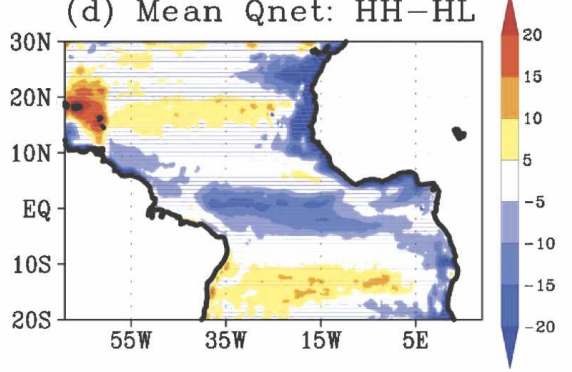

(f) Mean Qrad: $\mathrm{HH}-\mathrm{HL}$

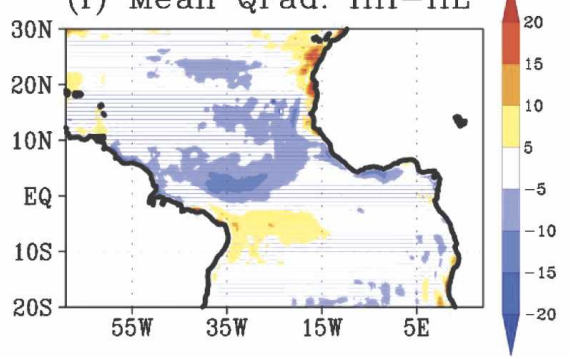

FIG. 11. (a) Six-year mean SST $\left({ }^{\circ} \mathrm{C}\right)$ in HH. (b)-(f) The mean difference with HL (HH minus HL) of (b) SST, (c) 10-m wind speed (shaded) and direction (arrows), and heat flux (W $\mathrm{m}^{-2}$ ), (d) net surface, (e) surface latent, and (f) net surface radiative. The negative (positive) in heat flux cools (warms) the ocean.

dynamical consequences for the ocean. The details of mixed layer heat budget calculations can reveal the dynamical and thermodynamical balances in SST, mixed layer depth and net surface heat, and freshwater fluxes. Such an analysis is beyond the scope of this paper and will be reported elsewhere.

The warming along the west coast of Africa in Fig. 11a deserves some attention. It is likely that the coastal warming in $\mathrm{HH}$ is simply due to the altered near-coastal winds, which drive reductions in upwelling and openocean Ekman advection of SST gradients. However, the details of the atmospheric land-sea mask are very different in the $\mathrm{HL}$ and $\mathrm{HH}$ cases, due to the enhanced resolution in $\mathrm{HH}$. Since an interpolation-extrapolation scheme is used to map the atmospheric fields to the oceanic grids, the small-scale structures in the $\mathrm{HH}$ land-sea mask play an important role in establishing the near-coastal alongshore upwelling-downwelling wind fields. In the both $\mathrm{HL}$ and $\mathrm{HH}$, the land-sea mask was qualitatively optimized to attempt to reduce the mismatch between oceanic and atmospheric grids and the misrepresentation of fluxes due to spectral truncations errors (Gibbs phenomenon). But it is not completely clear whether a different interpolation scheme for $\mathrm{HH}$ and HL (and/or a smoother land-sea mask) would result in similarly warmer SST along the coast in case HH. Nonetheless, this study focuses on the basinscale SST changes and its meridional gradient, not the changes in SST concentrated in the narrow band along the coast, which appear to be too localized to generate the basinwide effects.

\section{Conclusions and discussion}

A regional coupled climate model has been configured for the tropical Atlantic in the present study to explore the climatic importance of synoptic-scale atmospheric disturbances originating from the African con- 
(a)

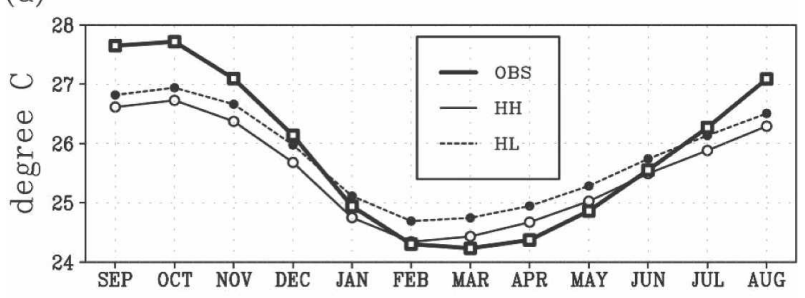

(b)

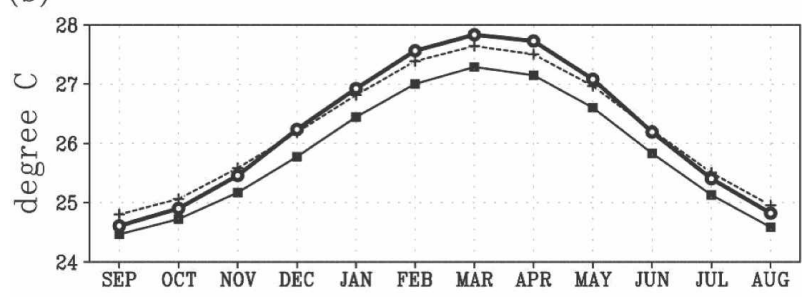

(c)

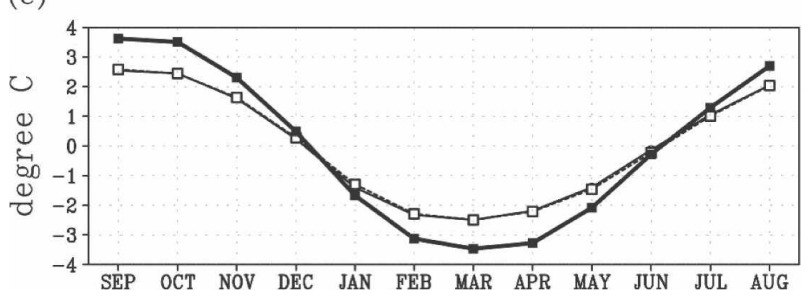

FIG. 12. (a) Seasonal cycle of monthly averaged SST (19992004 ) over $5^{\circ}-25^{\circ} \mathrm{N}, 50^{\circ}-20^{\circ} \mathrm{W}$ for the observations from TRMM SST (thick solid), HH (thin solid), and HL (thin dashed). (b) Same as (a), but for the Southern Hemisphere in $5^{\circ}-25^{\circ} \mathrm{S}, 50^{\circ}-$ $20^{\circ} \mathrm{W}$. (c) Same as (a), but for the seasonal cycle of meridional gradient of SST anomaly. SST gradient is computed as the difference in SST anomaly in the northern extratropics $\left(5^{\circ}-25^{\circ} \mathrm{N}, 50^{\circ}-\right.$ $\left.20^{\circ} \mathrm{W}\right)$ and the southern extratropics $\left(5^{\circ}-25^{\circ} \mathrm{S}, 50^{\circ}-20^{\circ} \mathrm{W}\right)$.

tinent. The analyses have shown that these synopticscale easterly waves are reasonably well simulated in the model with similar strengths both on $1^{\circ}$ and $1 / 4^{\circ}$ atmospheric grids. The simulated wave characteristics, including their amplitudes, are comparable between the model simulations, and the phases of the waves are similar to those of the RA2 fields that drive the regional models.

Strong cyclonic shear of the wind is generated in the easterly waves both in $\mathrm{HH}$ and $\mathrm{HL}$, although this wind shear is accompanied by heavy precipitation events only in HH, not in HL (Fig. 3). This is because the computed convergence in $\mathrm{HH}$ is much larger than in HL (Fig. 4), which leads to stronger convection and heavier precipitation (Figs. 5, 6). This propensity for higher convergence in the high-resolution case compares well with QuikSCAT observations of winds and clearly represents an improvement over the low-resolution case (Fig. 7).

The climatic importance of AEW-related convergence and convection processes is that they can lead to a more realistic model precipitation climatology and seasonality over the Atlantic Ocean (Figs. 9, 10). The occurrences of extreme rainfall events are much more realistic in $\mathrm{HH}$ and resemble rainfall measurements from the PIRATA buoy. These heavy rainfall events, occurring on the 2-6-day time scales associated with the easterly waves, account for a significant fraction $(>60 \%-70 \%)$ of the simulated variance of precipitation (Fig. 8), which implies a considerable alteration of the larger-scale annual mean rainfall due to these heavy rainfall events.

This improvement in the simulation of mean precipitation and the seasonal migration of ITCZ in the SCOAR model does not appear to be directly related to changes in the mean meridional SST gradient, which remain the same in both $\mathrm{HH}$ and HL (Figs. 11, 12). The location of the ITCZ is largely well captured in both simulations, but the convection associated with the AEWs in $\mathrm{HH}$ enhances the precipitation, which yields a more realistic ITCZ. This results in enhanced crossequatorial southerlies, which leads to stronger largescale convergence into the ITCZ (Gill 1980).

The details of the AEWs including the mechanism(s) of generation, life cycle, and the connection to the convection and hurricanes are not fully understood despite their important role in regulating precipitation and regional climate (Thorncroft et al. 2003; Mekonnen et al. 2006). The resultant small-scale atmospheric convergence and convection processes cannot be realistically resolved in the coupled GCMs that are used for climate prediction in this region primarily due to the coarseness of the atmospheric grids. As a result, these models commonly exhibit large systematic errors in the tropical Atlantic Ocean (Davey et al. 2002) and over western African nations (CLIVAR 2000). Our study here proposes that these climate models require higher horizontal resolution for better capturing the observed scale of convergence and convection. Higher horizontal resolution allows heavier precipitation events in the model that skew overall rainfall distributions toward longer tails, which can alter the mean large-scale climate in this region.

One of the foci of the international project called the African Monsoon Multidisciplinary Analysis (AMMA; Redelsperger et al. 2006) is to understand western African climate variability on multi-spatial-temporal scales and its complex interactions in the western African region. On the atmospheric mesoscale, the AMMA aims to study the typical rain-producing processes associated with the synoptic easterly waves and the African easterly jet, and their connection to the larger-scale climate variability. The current study directly addresses this issue by substantiating that 1 ) the 
transient synoptic-scale easterly waves that capture cyclonic wind shear and 2) the fine horizontal resolution that facilitates low-level convergence and convection are both essential to climate models to generate realistic and much improved mean precipitation climatologies.

Acknowledgments. This work forms part of the Ph.D. dissertation of HS. This research was partially funded by NOAA Grant, "Impact of oceanic mesoscale variability on the coupled climate." We gratefully acknowledge additional funding support from DOE (DE-FG0204ER63857) and NOAA (NA17RJ1231 through ECPC). The views expressed herein are those of the authors and do not necessarily reflect the views of these agencies. We thank the anonymous reviewers for their comments and suggestions, which substantially improved the manuscript. We also thank Joe Tribbia, Phil Rasch, Masao Kanamitsu, and Hideki Kanamaru for stimulating discussions and Stephen Yeager for providing the QuikSCAT daily wind product. The Center for Observations, Modeling and Prediction at Scripps (COMPAS) provided indispensable computer time. The Tropical Rainfall Measuring Mission (TRMM) Microwave Imager (TMI) SST data were obtained from the Web site of Remote Sensing Systems (http://www. ssmi.com). The GPCP precipitation and NCEP/DOE Reanalysis II were provided by the NOAA/OAR/ ESRL PSD, Boulder, Colorado, from its Web site (http://www.cdc.noaa.gov). The PIRATA data were obtained from the Web site of NOAA PMEL (http:// www.pmel.noaa.gov/tao).

\section{REFERENCES}

Albignat, J. P., and R. J. Reed, 1980: The origin of African wave disturbances during Phase III of GATE. Mon. Wea. Rev., 108, 1827-1839.

Arakawa, A., and W. H. Schubert, 1974: Interaction of a cumulus cloud ensemble with large-scale environment, Part I. J. Atmos. Sci., 31, 674-704.

Avila, L. A., and R. J. Pasch, 1992: Atlantic tropical systems of 1991. Mon. Wea. Rev., 120, 2688-2696.

Berry, G. J., and C. D. Thorncroft, 2005: Case study of an intense African easterly wave. Mon. Wea. Rev., 133, 752-766.

Biasutti, M., A. H. Sobel, and Y. Kushnir, 2006: AGCM precipitation biases in the tropical Atlantic. J. Climate, 19, 935-958.

Burpee, R. W., 1972: The origin and structure of easterly waves in the lower troposphere of North Africa. J. Atmos. Sci., 29, 77-90.

Carlson, T. N., 1969: Some remarks on African disturbances and their progress over the tropical Atlantic. Mon. Wea. Rev., 97, 716-726.

Chang, P., L. Ji, and H. Li, 1997: A decadal climate variation in the tropical Atlantic Ocean from thermodynamic air-sea interactions. Nature, 385, 516-518.

Charney, J. G., and M. E. Stern, 1962: On the stability of internal baroclinic jets in a rotating atmosphere. J. Atmos. Sci., 19, 159-172.

Chiang, J. C. H., Y. Kushnir, and A. Giannini, 2002: Deconstructing Atlantic Intertropical Convergence Zone variability: Influence of the local cross-equatorial sea surface temperature gradient and remote forcing from the eastern equatorial $\mathrm{Pa}-$ cific. J. Geophys. Res., 107, 4004, doi:10.1029/2000JD000307.

CLIVAR, 2000: CLIVAR Africa implementation plan. WCRP Informal Rep. 5/2000, ICPO Publication Series 35, 35 pp.

Cook, K. H., 1999: Generation of the African easterly jet and its role in determining West African precipitation. J. Climate, 12, $1165-1184$.

Dai, A. G., and T. M. L. Wigley, 2000: Global patterns of ENSOinduced precipitation. Geophys. Res. Lett., 27, 1283-1286.

Davey, M., and Coauthors, 2002: STOIC: A study of coupled model climatology and variability in tropical ocean regions. Climate Dyn., 18, 403-420.

Enfield, D. B., and D. A. Mayer, 1997: Tropical Atlantic sea surface temperature variability and its relation to El NiñoSouthern Oscillation. J. Geophys. Res., 102, 929-946.

Fairall, C. W., E. F. Bradley, D. P. Rogers, J. B. Edson, and G. S. Young, 1996: Bulk parameterization of air-sea fluxes for Tropical Ocean-Global Atmosphere Coupled Ocean-Atmosphere Response Experiment. J. Geophys. Res., 101, 37473764.

Folland, C. K., T. N. Palmer, and D. E. Parker, 1986: Sahel rainfall and worldwide sea temperatures, 1901-85. Nature, 320, 602607.

Frank, N. L., 1970: Atlantic tropical systems of 1969. Mon. Wea. Rev., 98, 307-314.

Gill, A. E., 1980: Some simple solutions for heat-induced tropical circulations. Quart. J. Roy. Meteor. Soc., 106, 447-462.

Gu, G., R. F. Adler, G. J. Huffman, and S. Curtis, 2004: African easterly waves and their association with precipitation. $J$. Geophys. Res., 109, D04101, doi:10.1029/2003JD003967.

Haidvogel, D. B., H. G. Arango, K. Hedstrom, A. Beckmann, P. Malanotte-Rizzoli, and A. F. Shchepetkin, 2000: Model evaluation experiments in the North Atlantic Basin: Simulations in nonlinear terrain-following coordinates. Dyn. Atmos. Oceans, 32, 239-281.

Hastenrath, S., and L. Heller, 1977: Dynamics of climate hazards in northeast Brazil. Quart. J. Roy. Meteor. Soc., 103, 77-92.

— northeast Brazil rainfall anomalies. J. Geophys. Res., 98, 5093-5102.

Hsieh, J.-S., and K. H. Cook, 2005: Generation of African easterly wave disturbances: Relationship to the African easterly jet. Mon. Wea. Rev., 133, 1311-1327.

Juang, H.-M. H., and M. Kanamitsu, 1994: The NMC nested regional spectral model. Mon. Wea. Rev., 122, 3-26.

_ spectral model: An update. Bull. Amer. Meteor. Soc., 78, 2125-2143.

Kalnay, E., and Coauthors, 1996: The NCEP/NCAR 40-Year Reanalysis Project. Bull. Amer. Meteor. Soc., 77, 437-471.

Kanamaru, H., and M. Kanamitsu, 2007: Scale-selective bias correction in a downscaling of global analysis using a regional model. Mon. Wea. Rev., 135, 334-350.

Kanamitsu, M., and Coauthors, 2002a: NCEP dynamical seasonal forecast system 2000. Bull. Amer. Meteor. Soc., 83, 10191037.

, W. Ebisuzaki, J. Woollen, S.-K. Yang, J. J. Hnilo, M. Fiorino, 
and G. L. Potter, 2002b: NCEP-DOE AMIP-II Reanalysis (R-2). Bull. Amer. Meteor. Soc., 83, 1631-1643.

— H. Kanamaru, Y. Cui, and H.-M. H. Juang, 2005: Parallel implementation of the regional spectral atmospheric model. PIER Project Rep. CEC-500-2005-014, 23 pp.

Kilades, G. N., C. D. Thorncroft, and N. M. J. Hall, 2006: Threedimensional structure and dynamics of African easterly waves. Part I: Observations. J. Atmos. Sci., 63, 2212-2230.

Landsea, C. W., G. D. Bell, W. M. Gray, and S. B. Goldenberg, 1998: The extremely active 1995 Atlantic hurricane season: Environmental conditions and verification of seasonal forecasts. Mon. Wea. Rev., 126, 1174-1193.

Laprise, R., 1992: The resolution of global spectral models. Bull. Amer. Meteor. Soc., 73, 1453-1454.

Lindzen, R. S., and S. Nigam, 1987: On the role of sea surface temperature gradients in forcing low-level winds and convergence in the tropics. J. Atmos. Sci., 44, 2418-2436.

Lonfat, M., F. D. Marks Jr., and S. S. Chen, 2004: Precipitation distribution in tropical cyclones using the Tropical Rainfall Measuring Mission (TRMM) microwave imager: A global perspective. Mon. Wea. Rev., 132, 1645-1660.

Mekonnen, A., C. D. Thorncroft, and A. R. Aiyyer, 2006: Analysis of convection and its association with African easterly waves. J. Climate, 19, 5405-5421.

Moorthi, S., and M. J. Suarez, 1992: Relaxed Arakawa-Schubert. A parameterization of moist convection for general circulation models. Mon. Wea. Rev., 120, 978-1002.

Nobre, P., and J. Shukla, 1996: Variations of sea surface temperature, wind stress, and rainfall over the tropical Atlantic and South America. J. Climate, 9, 2464-2479.

Palmer, T., 1986: Influence of Atlantic, Pacific, and Indian oceans on Sahel rainfall. Nature, 322, 251-253.

Pauluis, O., and S. Garner, 2006: Sensitivity of radiative-convective equilibrium simulations to horizontal resolution. $J$. Atmos. Sci., 63, 1910-1923.

Payne, S. W., and M. M. McGarry, 1977: The relationship of satellite inferred convective activity to easterly waves over West Africa and the adjacent ocean during Phase III of GATE. Mon. Wea. Rev., 105, 413-420.

Peng, M. S., B. Fu, T. F. Hogan, and T. Li, 2006: On African easterly waves that impacted two tropical cyclones in 2004. Geophys. Res. Lett., 33, L11807, doi:10.1029/2006GL026038.

Pielke, R. A., 1991: A recommended specific definition of "resolution.” Bull. Amer. Meteor. Soc., 72, 1914.
Pytharoulis, I., and C. D. Thorncroft, 1999: The low-level structure of African easterly waves in 1995. Mon. Wea. Rev., 127, 2266-2280.

Redelsperger, J.-L., C. D. Thorncroft, A. Diedhiou, T. Lebel, D. J. Parker, and J. Polcher, 2006: African monsoon multidisciplinary analysis: An international research project and field campaign. Bull. Amer. Meteor. Soc., 87, 1739-1746.

Reed, R. J., D. C. Norquist, and E. E. Recker, 1977: The structure and properties of African wave disturbances as observed during Phase III of GATE. Mon. Wea. Rev., 105, 317-333.

Rennick, M. A., 1976: The generation of African waves. J. Atmos. Sci., 33, 1955-1969.

Saravanan, R., and P. Chang, 2000: Interaction between tropical Atlantic variability and El Niño-Southern Oscillation. J. Climate, 13, 2177-2194.

Seo, H., M. Jochum, R. Murtugudde, and A. J. Miller, 2006: Effect of ocean mesoscale variability on the mean state of tropical Atlantic climate. Geophys. Res. Lett., 33, L09606, doi:10.1029/ 2005 GL025651.

— A. J. Miller, and J. O. Roads, 2007: The Scripps Coupled Ocean-Atmosphere Regional (SCOAR) Model, with applications in the eastern Pacific sector. J. Climate, 20, 381-402.

Shchepetkin, A. F., and J. C. McWilliams, 2005: The regional oceanic modeling system (ROMS): A split-explicit, free-surface, topography-following-coordinate ocean model. Ocean Modell., 9, 347-404.

Thorncroft, C. D., and K. Hodges, 2001: African easterly wave variability and its relationship to Atlantic tropical cyclone activity. J. Climate, 14, 1166-1179.

— , and Coauthors, 2003: The Jet2000 Project: Aircraft observations of the African easterly jet and African easterly waves. Bull. Amer. Meteor. Soc., 84, 337-351.

Xie, P., and P. A. Arkin, 1997: Global precipitation: A 17-year monthly analysis based on gauge observations, satellite estimates, and numerical model outputs. Bull. Amer. Meteor. Soc., 78, 2539-2558.

Xie, S.-P., and J. A. Carton, 2004: Tropical Atlantic variability: Patterns, mechanisms, and impacts. Earth's Climate: The Ocean-Atmosphere Interaction, Geophys. Monogr., Vol. 147, Amer. Geophys. Union, 121-142.

Zebiak, S. E., 1993: Air-sea interaction in the equatorial Atlantic region. J. Climate, 6, 1567-1586. 